\title{
Fuzzy Sliding Mode Control for the Vehicle Height and Leveling Adjustment System of an Electronic Air Suspension
}

\author{
Xiao-Qiang Sun ${ }^{1 *}\left(\mathbb{D}\right.$, Ying-Feng Cai ${ }^{1}$, Chao-Chun Yuan', Shao-Hua Wang ${ }^{2}$ and Long Chen ${ }^{1}$
}

\begin{abstract}
The accurate control for the vehicle height and leveling adjustment system of an electronic air suspension (EAS) still is a challenging problem that has not been effectively solved in prior researches. This paper proposes a new adaptive controller to control the vehicle height and to adjust the roll and pitch angles of the vehicle body (leveling control) during the vehicle height adjustment procedures by an EAS system. A nonlinear mechanism model of the full-car vehicle height adjustment system is established to reflect the system dynamic behaviors and to derive the system optimal control law. To deal with the nonlinear characters in the vehicle height and leveling adjustment processes, the nonlinear system model is globally linearized through the state feedback method. On this basis, a fuzzy sliding mode controller (FSMC) is designed to improve the control accuracy of the vehicle height adjustment and to reduce the peak values of the roll and pitch angles of the vehicle body. To verify the effectiveness of the proposed control method more accurately, the full-car EAS system model programmed using AMESim is also given. Then, the co-simulation study of the FSMC performance can be conducted. Finally, actual vehicle tests are performed with a city bus, and the test results illustrate that the vehicle height adjustment performance is effectively guaranteed by the FSMC, and the peak values of the roll and pitch angles of the vehicle body during the vehicle height adjustment procedures are also reduced significantly. This research proposes an effective control methodology for the vehicle height and leveling adjustment system of an EAS, which provides a favorable control performance for the system.
\end{abstract}

Keywords: Electronic air suspension, Height adjustment, Leveling control, Fuzzy sliding mode control, Vehicle tests

\section{Introduction}

Since the first application of electronic technology to the vehicle air suspension system recorded in 1980s, electronic air suspension (EAS) system has gained wide attentions [1-4]. The main advantage of EAS system is the improvement of the vehicle dynamic performance, including the driving comfort, the handling stability and the fuel economy $[5,6]$. As a well-established vehicle suspension system, EAS system has been researched in depth and been used in a large number of vibration isolation occasions, such as the vehicle seat suspension and the railway vehicle suspension [7-10]. However, the

\footnotetext{
*Correspondence: sunxqujs@126.com

1 Automotive Engineering Research Institute, Jiangsu University, Zhenjiang 212013, China

Full list of author information is available at the end of the article
}

vehicle height and leveling adjustment control problem of an EAS system still poses difficulties for researchers, which are reflected in the previous academic reports on this theme. The progresses of the intelligent control theories together with the increasing compute capability of the relevant hardware allow solving the control problem from a new perspective $[8,9]$. In this paper, a fuzzy sliding mode control (FSMC) approach for precise vehicle height adjustment and leveling the vehicle body at appropriate posture by an EAS system is presented.

The heights at four corners of the vehicle body are adjusted by controlling the air mass flow rates flowing into or flowing out of the air springs for an EAS system. During off-road driving condition, the EAS system can lift the vehicle body to prevent the suspension from hitting the position limiter [10], while for driving on an expressway with high speed, the air drag can be reduced
Springer Open

(c) The Author(s) 2018. This article is distributed under the terms of the Creative Commons Attribution 4.0 International License (http://creativecommons.org/licenses/by/4.0/), which permits unrestricted use, distribution, and reproduction in any medium, provided you give appropriate credit to the original author(s) and the source, provide a link to the Creative Commons license, and indicate if changes were made. 
and the driving safety can be enhanced by lowering the vehicle body. Meanwhile, in order to prevent the phenomenon of vehicle posture instability, i.e., the peak values of the roll and pitch angles of the vehicle body are too large, which is mainly caused by the different payloads at four corners and the system parameters difference between the front and rear air suspensions, the effective control of the vehicle leveling is also very essential for the EAS system dynamic performance [11].

The difficulties in controlling the vehicle height and leveling of an EAS system arise from several aspects. In general, the controller needs to adjust the air mass flow rates flowing into or flowing out of the four air springs synchronously with several on-off solenoid valves. Furthermore, the nonlinear dynamic behaviors of the air spring will also give some troubles to the derivation of the system control law. In particular, the vehicle height and leveling control problem is further complicated by the real-time variations of the payloads and the system parameters [12]. In that case, only robust control methods could be effective. In Ref. [13], Kim and Lee proposed a sliding mode control (SMC) strategy for solving the height and leveling control problem of a closed-loop EAS system. Although the control method is robust and the system performance is improved, the controller may be sensitive to external disturbances due to the fixed control parameters. Xu et al. [14] proposed a variable structure vehicle height control method for single-wheel air suspension system, and on this basis, by calculating the deviations of the pitch and roll angles of the vehicle body, a leveling controller is also designed based on the fuzzy logic control (FLC) algorithm. However, due to the separated design of the vehicle height and leveling controller, the overall control system design procedure is lack of systematic character and fault tolerance.

Since the system uncertainties can be dealt with directly under the control of the SMC method, many SMC applications in engineering have been reported. Nevertheless, the SMC methodology without adaptive capability may suffer from chattering problem in control [15]. Several approaches have been proposed to eliminate the chattering phenomenon. However, these approaches, which are based on the use of a boundary layer in the sliding mode, are known to degrade the robustness [16]. To conquer the vulnerability of single SMC method and guarantee the system stability, the combination of SMC and FLC could be useful [17]. Many publications have reported effective schemes to apply fuzzy sliding mode control (FSMC) method for the controller design of several high-order nonlinear systems [18-21].

The main contribution of this paper is that a novel control approach is proposed by combining the merits of SMC and FLC to address the vehicle height and leveling control problem of a full-car EAS system. The FSMC is designed by defining a switching sliding surface for the system, whose slope is modified by a FLC system. On this basis, the switching surface is also used as an input to FLC, thus the continuous term of SMC can be computed by using equivalent method. One advantage of the proposed approach is that the chattering control phenomenon is attenuated. Another advantage of the method is that the system controller has higher adaptive ability for the external disturbances. As far as we know, this approach is efficiently applied for the vehicle height and leveling control problem of an EAS system for the first time.

The organization of this paper is as follows: The EAS system dynamics, leveling control problem and the system nonlinear mathematical model are presented in Section 2. In Section 3, the design method for the FSMC of the EAS system is described. Section 4 illustrates various aspects of the controller behaviors with co-simulation conducted based on Matlab and AMESim. The actually potential advantages of the control method are verified in Section 5 by actual vehicle tests. The conclusions of this paper are finally summarized in Section 6.

\section{System Description and Modeling}

\subsection{System Outline}

The target vehicle height and leveling adjustment system of a full-car EAS is shown in Figure 1. Four air suspensions, which consist of four air springs and four dampers with assumedly constant damping coefficient, are installed at each corner of the vehicle. The vehicle height and leveling adjustment system is composed of six on-off solenoid valves deciding the air flow path, a compressor and an air reservoir providing the high-pressure air, an electronic control unit (ECU) providing control signals for the system, and some other related pneumatic components.

According to the architecture of the target system, the vehicle height and leveling control procedures can be summarised as follows [22-24].

(1) Height and leveling adjustment during the lifting procedure: In the lifting process, the charging solenoid valve or the compressor is opened, thus the compressed air can flow into the four air springs. If the vehicle body does not maintain at an appropriate posture, the control signals for the four air spring solenoid valves would be reassigned to reduce the air mass flow rates flowing into the air springs whose height lifting speed are relatively fast.

(2) Height and leveling adjustment during the lowering procedure: To lower the vehicle body, the ECU generates control signals to open the discharging sole- 


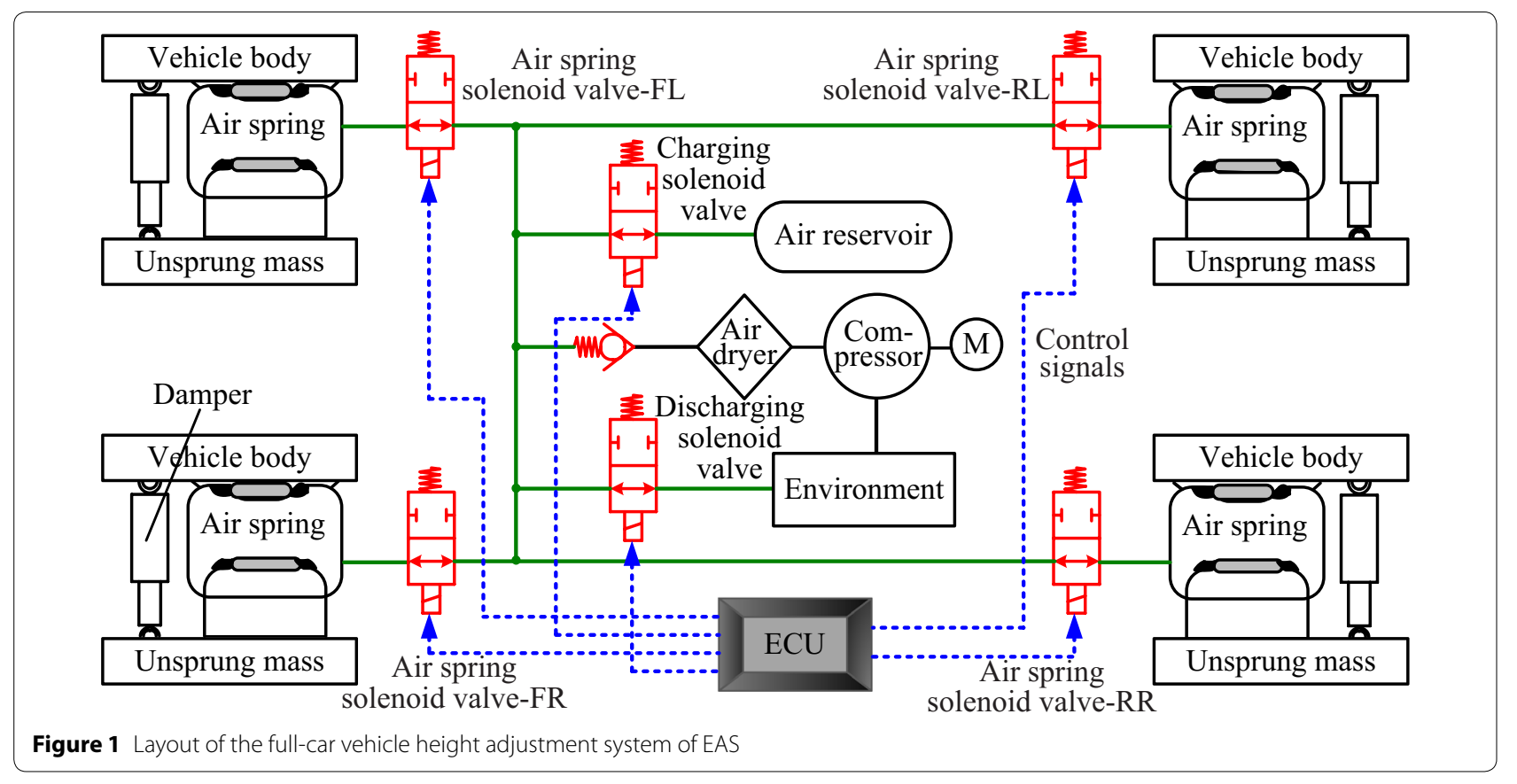

noid valve and the air spring solenoid valves, thus the compressed air in the air springs can flow into the environment directly. Similarly, if the vehicle body does not maintain at an appropriate posture in the height lowering procedure, the air mass flow rates flowing out of the air springs whose height lowering speed are relatively fast would be reduced.

\subsection{Leveling Control Problem}

Due to the maldistribution of the vehicle payloads and the system parameters difference between the front and rear air suspensions, it is difficult to maintain the synchronous vehicle height adjustments at four corners of the vehicle body without coordination control. The vehicle leveling instability can not only reduce the ride comfort, but also have a marked impact on the vehicle handling performance. The vehicle leveling instability originated by the desynchronized height adjustment is shown in Figure 2. Among them, the vehicle pitch angle originated by the desynchronized height adjustment between the front and rear air suspensions in the height lifting process is illustrated in Figure 2(a), the vehicle roll angle originated by the desynchronized vehicle height adjustment between the right and left air suspensions in the height lowering process is illustrated in Figure 2(b).

In the figures, $z_{a-i}^{f r}, z_{a-i}^{f l}, z_{a-i}^{r l}$ and $z_{a-i}^{r r}$ are the initial vehicle heights at four corners of the vehicle body,

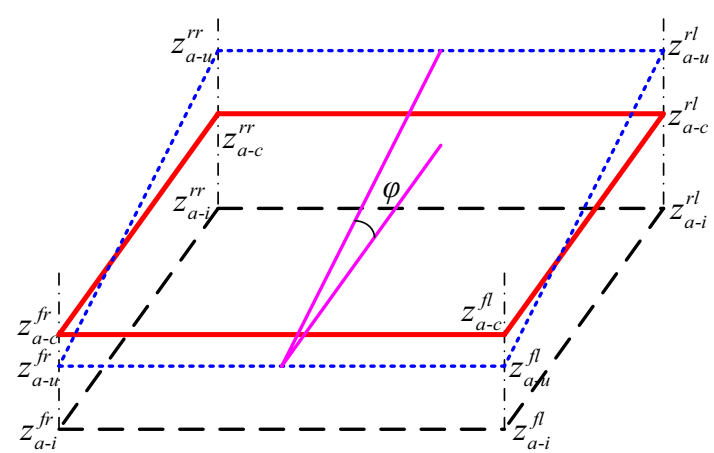

a Vehicle pitch angle

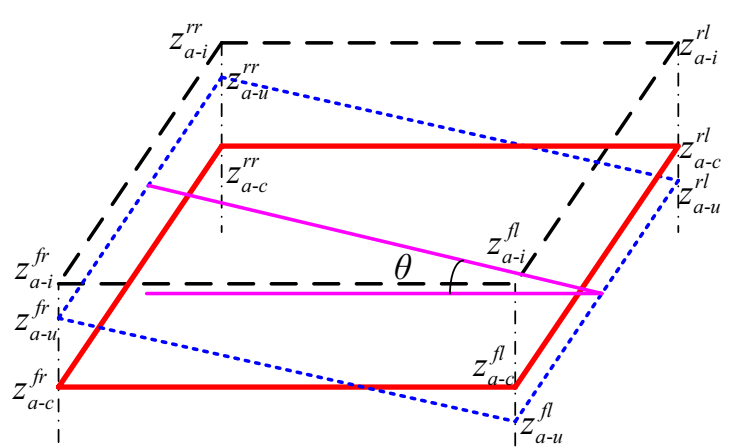

b Vehicle roll angle

Figure 2 Vehicle leveling instability 
$z_{a-u}^{f}, z_{a-u}^{f}, z_{a-u}^{r l}$ and $z_{a-u}^{r r}$ are the vehicle heights at four corners without coordination control, $z_{a-c}^{f r}, z_{a-c}^{f}, z_{a-c}^{r l}$ and $z_{a-c}^{r r}$ are the vehicle heights at four corners under ideal control, $\theta$ and $\phi$ denote the roll and pitch angles of the vehicle body. In order to prevent the phenomenon of vehicle leveling instability, the control system needs to adjust the air mass flow rates flowing into or flowing out of the air springs effectively during the vehicle height lifting or lowering procedures.

\subsection{System Modeling}

The mechanism model describing the nonlinear dynamic behaviors of the vehicle height and leveling adjustment system of EAS consists of the model describing the thermodynamic behaviors of the air springs, the model describing the airflow properties of the solenoid valves and the full-car dynamic model.

\subsubsection{Thermodynamic Behaviors of the Air Spring}

During the vehicle height and leveling adjustment procedures, the dynamic behaviors of the air springs are similar to a variable mass gas charging/discharging thermodynamic system. Based on the derivation of the relevant thermodynamic theories, the thermodynamic behaviors of the air spring are given as $[25,26]$

$$
\dot{P}_{a s} V_{a s}=\kappa R T\left(q_{\text {in }}-q_{\text {out }}\right)-\kappa P_{a s} \dot{V}_{a s},
$$

where $P_{a s}$ is the air pressure inside the air spring, $V_{a s}$ is the volume of the air spring, $\kappa$ refers to the polytropic constant, $R$ denotes the universal gas constant, $T$ is the temperature of the air inside the air spring, $q_{\text {in }}$ and $q_{\text {out }}$ are the air mass flow rates flowing into and flowing out of the air spring respectively.

The pipe can also be considered as a variable mass gas charging/discharging thermodynamic system, but its volume remains constant in the vehicle height and leveling adjustment procedures, thus the mechanism model of the pipe can be given as

$$
\dot{P}_{p i} V_{p i}=\kappa R T\left(q_{p i-i n}-q_{p i-o u t}\right),
$$

where $P_{p i}$ is the air pressure inside the pipe, $V_{p i}$ is the volume of the pipe, $q_{p i-i n}$ and $q_{p i-o u t}$ are the air mass flow rates flowing into and flowing out of the pipe.

\subsubsection{Solenoid Valve Airflow Properties}

The air mass flow rate through the solenoid valve is mainly decided by the upstream and downstream air pressures of the solenoid valve. Based on the modeling assumptions, the on-off solenoid valve is abstracted to a thin wall orifice, thus the nonlinear air mass flow characteristics through the solenoid valve is expressed mathematically as $[27,28]$ $q\left(p_{u}, p_{d}\right)= \begin{cases}s \frac{p_{u}}{\sqrt{R T}} \sqrt{\kappa\left(\frac{2}{\kappa+1}\right)^{\frac{\kappa+1}{\kappa-1}}}, & 0<\frac{p_{d}}{p_{u}} \leq b, \\ s \sqrt{\frac{2}{R T}} \sqrt{p_{d}\left(p_{u}-p_{d}\right)}, & b<\frac{p_{d}}{p_{u}} \leq 1,\end{cases}$

where $q\left(P_{u}, P_{d}\right)$ refers to the air mass flow rate through the solenoid valve, $s$ denotes the solenoid valve crosssectional area, $P_{u}$ refers to the upstream air pressure, $P_{d}$ refers to the downstream air pressure, and $b$ refers to the critical pressure ratio. It is noted that the airflow characteristics of the six on-off solenoid valves are assumed to be identical to each other.

\subsubsection{Full-car Dynamic Model}

The motion equations of the full-car dynamic model can be presented mathematically as [29]

$$
\begin{aligned}
m_{s} \ddot{z}_{s}= & F_{s 1}+F_{s 2}+F_{s 3}+F_{s 4}=P_{a s 1} A_{a s 1} \\
& +c_{d 1}\left(\dot{z}_{f r}-\dot{z}_{a 1}\right)+P_{a s 2} A_{a s 2}+c_{d 2}\left(\dot{z}_{f l}-\dot{z}_{a 2}\right) \\
& +P_{a s 3} A_{a s 3}+c_{d 3}\left(\dot{z}_{r l}-\dot{z}_{a 3}\right) \\
& +P_{a s 4} A_{a s 4}+c_{d 4}\left(\dot{z}_{r r}-\dot{z}_{a 4}\right), \\
I_{\theta} \ddot{\theta}= & F_{s 2} l_{a}+F_{s 3} l_{a}-F_{s 1} l_{a}-F_{s 4} l_{a} \\
I_{\varphi} \ddot{\varphi}= & F_{s 1} l_{f}+F_{s 2} l_{f}-F_{s 3} l_{r}-F_{s 4} l_{r}, \\
m_{f r} \ddot{z}_{f r}= & k_{t f}\left(z_{r 1}-z_{f r}\right)-P_{a s 1} A_{a s 1}-c_{d 1}\left(\dot{z}_{f r}-\dot{z}_{a 1}\right), \\
m_{f l} \ddot{z}_{f l}= & k_{t f}\left(z_{r 2}-z_{f l}\right)-P_{a s 2} A_{a s 2}-c_{d 2}\left(\dot{z}_{f l}-\dot{z}_{a 2}\right), \\
m_{r l} \ddot{z}_{r l}= & k_{t r}\left(z_{r 3}-z_{r l}\right)-P_{a s 3} A_{a s 3}-c_{d 3}\left(\dot{z}_{r l}-\dot{z}_{a 3}\right), \\
m_{r r} \ddot{z}_{r r}= & k_{t r}\left(z_{r 4}-z_{r r}\right)-P_{a s 4} A_{a s 4}-c_{d 4}\left(\dot{z}_{r r}-\dot{z}_{a 4}\right),
\end{aligned}
$$

where $m_{s}$ refers to the sprung mass, $z_{s}$ refers to the vertical displacement of the vehicle body, $F_{s i}(i=1,2,3,4)$ denote the applied forces exerted on the vehicle body by the four air suspensions, $P_{a s i}(i=1,2,3,4)$ denote the pressures of the air in the air springs, $c_{d i}(i=1,2,3,4)$ refer to the damping coefficients of the four dampers, $A_{a s i}$ $(i=1,2,3,4)$ refer to the effective areas of the air springs, $z_{f r}, z_{f l}, z_{r r}$ and $z_{r l}$ are the vertical displacements of the four unsprung masses, $z_{a i}(i=1,2,3,4)$ refer to the displacements of the vehicle body at four corners, $I_{\theta}$ and $I_{\phi}$ refer to the roll and pitch moments of inertia respectively, $l_{a}$ is half of the wheel-track, $l_{f}$ and $l_{r}$ refer to the distances between the vehicle centroid to the front and the rear axis, $m_{f r}, m_{f l}, m_{r r}$ and $m_{r l}$ are the four unsprung masses, $k_{t f}$ and $k_{t r}$ are the tyre stiffnesses of the front and rear wheels respectively, $z_{r i}(i=1,2,3,4)$ are the road roughness inputs.

Since the amplitudes of the roll and pitch motions of the vehicle body are relatively small, the following linear geometrical relationships between the vertical displacements of the vehicle body at four corners and $z_{s}, \theta$ and $\phi$ can be obtained as [30] 


$$
\begin{aligned}
& z_{a 1}=z_{s}+l_{f} \varphi-l_{a} \theta, \\
& z_{a 2}=z_{s}+l_{f} \varphi+l_{a} \theta, \\
& z_{a 3}=z_{s}-l_{r} \varphi+l_{a} \theta, \\
& z_{a 4}=z_{s}-l_{r} \varphi-l_{a} \theta,
\end{aligned}
$$

Based on the above equations, the vehicle height and leveling adjustment system model of EAS is a typical multi-input multi-output system. Among these, the system state variables can be defined as

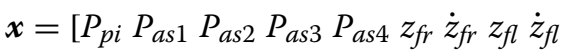

$$
\begin{aligned}
& \left.z_{r l} \dot{z}_{r l} z_{r r} \dot{z}_{r r} z_{s} \dot{z}_{s} \theta \dot{\theta} \varphi \dot{\varphi}\right]^{\mathrm{T}} \text {, }
\end{aligned}
$$

In order to achieve the effective control for the vehicle height and leveling by an EAS system, the air mass flow rates through the four air spring solenoid valves should be controlled, which are given according to Eq. (1) as

$$
q_{a s i}=q_{\text {ini }}-q_{\text {outi }} \quad(i=1,2,3,4),
$$

Therefore, with the four defined control inputs $q_{a s i}$ $(i=1,2,3,4)$, the system nonlinear mechanism model can be further obtained as

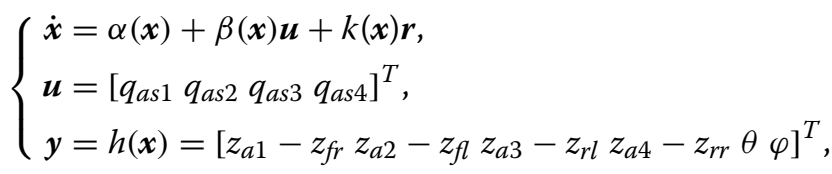

where $r$ refers to the road roughness disturbance. The specific contents of $\alpha(\boldsymbol{x}), \beta(\boldsymbol{x})$ and $k(\boldsymbol{x})$ can be obtained based on Eqs. (1), (2), (4) and (5), which are omitted here because of lack of space.

\section{Controller Design}

To conduct the derivation of FSMC control law for the vehicle height and leveling adjustment system of EAS in the linear field, the nonlinear mechanism model of the system needs to be further globally linearized through the state feedback method based on the differential geometry theory. The following are the related concepts of differential geometry theory [31].

For an affine nonlinear system

$$
\left\{\begin{array}{l}
\dot{\boldsymbol{x}}=f(\boldsymbol{x})+g(\boldsymbol{x}) \boldsymbol{u}, \\
\boldsymbol{y}=h(\boldsymbol{x})
\end{array}\right.
$$

where $\boldsymbol{x}$ refers to the system state variables, $f$ and $g$ are the smooth functions of the vector field $h, \boldsymbol{u}$ refers to the system inputs and $y$ refers to the system outputs.

Definition 1: Lie derivative Take the derivative of the system output equation $\overline{\boldsymbol{y}}=\frac{\mathrm{d} h}{\mathrm{~d} \boldsymbol{x}} \overline{\boldsymbol{x}}=\frac{\mathrm{d} h}{\mathrm{~d} \boldsymbol{x}}(f(\boldsymbol{x})+g(\boldsymbol{x}) \boldsymbol{u})=L_{f} h(\boldsymbol{x})+L_{g} h(\boldsymbol{x}) \boldsymbol{u}$,

where $L_{f} h(\boldsymbol{x})=\frac{\mathrm{d} h}{\mathrm{~d} \boldsymbol{x}} f(\boldsymbol{x})$ and $L_{g} h(\boldsymbol{x})=\frac{\mathrm{d} h}{\mathrm{~d} \boldsymbol{x}} g(\boldsymbol{x})$ are defined as the lie derivative.

Definition 2: Relative degree For $\boldsymbol{x}_{0} \in \boldsymbol{x}$, if the neighborhood of $x_{0}$ and a positive integer $r$, which make the system (9) meet the following conditions, exist,

$$
\left\{\begin{array}{l}
L_{g} L_{f}^{k} h(\boldsymbol{x})=0, \forall \boldsymbol{x} \in V, 0 \leq k<r-1 \\
L_{g} L_{f}^{r-1} h(\boldsymbol{x}) \neq 0, \forall \boldsymbol{x} \in V .
\end{array}\right.
$$

Then the relative degree of the system is defined as $r$.

Differential geometry theory is a controller design method for the nonlinear system. By using appropriate nonlinear state feedback and coordinate transformation method, a nonlinear system is transformed into a linear system partially or wholly, then the system controller can be designed based on the linear control method.

\subsection{Linearization of the System Model}

According to the specific contents of $\alpha(\boldsymbol{x})$ and $\beta(\boldsymbol{x})$, the following calculated results can be obtained based on the differential geometry theory

$$
\left\{\begin{array}{l}
L_{g_{j}} L_{f}^{0} h_{i}(\boldsymbol{x})=L_{g_{j}} h_{i}(\boldsymbol{x})=0, \\
L_{g_{j}} L_{f} h_{i}(\boldsymbol{x})=L_{g_{j}} L_{f}^{2} h_{i}(\boldsymbol{x})=0, \\
L_{g_{j}} L_{f}^{3} h_{i}(\boldsymbol{x})=L_{g_{j}} L_{f}^{4} h_{i}(\boldsymbol{x})=0, \\
L_{g_{j}} L_{f}^{5} h_{i}(\boldsymbol{x})=0, \quad L_{g_{j}} L_{f}^{6} h_{i}(\boldsymbol{x}) \neq 0,
\end{array}\right.
$$

where $i=j=6$. Thus the relative degree of the nonlinear system $\left\{r_{i}\right\}(i=1,2,3,4,5,6)=\{6\}$, which satisfies the necessary and sufficient conditions for the linearization of the system. Therefore, by introducing the following nonsingular coordinate transformation:

$Z=\left\{\begin{array}{l}Z_{1} \\ Z_{2} \\ Z_{3} \\ Z_{4} \\ Z_{5} \\ Z_{6}\end{array}\right\}, \quad$ where $Z_{i}=\left\{\begin{array}{r}z_{5 i-4} \\ z_{5 i-3} \\ z_{5 i-2} \\ z_{5 i-1} \\ z_{5 i} \\ L_{f}^{2} h_{i}(x)\end{array}\right\}, i=1, \ldots, 6$,

where $L_{f}^{k} h(\boldsymbol{x})=L_{f} L_{f}^{k-1} h(\boldsymbol{x})=\left(\partial\left(L_{f}^{k-1} h(\boldsymbol{x})\right) / \partial(x)\right) f(\boldsymbol{x})$, and $L f h(\boldsymbol{x})$ is called the lie derivative of $h$ with respect to $f$ [32], the nonlinear model of the vehicle height and leveling adjustment system of EAS is transformed into a new system model by the linearized coordinates. Then, the new system state equation in the linear space can be presented mathematically as 


$$
\dot{\boldsymbol{X}}=\left\{\begin{array}{c}
\dot{\boldsymbol{X}}_{1} \\
\dot{\boldsymbol{X}}_{2} \\
\dot{\boldsymbol{X}}_{3} \\
\dot{\boldsymbol{X}}_{4} \\
\dot{\boldsymbol{X}}_{5} \\
\dot{\boldsymbol{X}}_{6}
\end{array}\right\}, \quad \text { where } \boldsymbol{X}_{i}=\left\{\begin{array}{l}
x_{5 i-3} \\
x_{5 i-2} \\
x_{5 i-1} \\
x_{5 i} \\
x_{5 i+1} \\
L_{i}
\end{array}\right\}, i=1, \ldots, 6
$$

where

$$
\begin{aligned}
L_{i} & =L_{f}^{3} h_{i}(\boldsymbol{x})+L_{g 1} L_{f}^{2} h_{i}(\boldsymbol{x}) \boldsymbol{v}(1)+L_{g 2} L_{f}^{2} h_{i}(\boldsymbol{x}) \boldsymbol{v}(2) \\
& +L_{g 3} L_{f}^{2} h_{i}(\boldsymbol{x}) \boldsymbol{v}(3)+L_{g 4} L_{f}^{2} h_{i}(\boldsymbol{x}) \boldsymbol{v}(4),
\end{aligned}
$$

On this basis, the control inputs of the linear model in the new coordinates have the following relationship with the control inputs of the nonlinear model in the original coordinates

$$
v(\boldsymbol{x})=\boldsymbol{B}(\boldsymbol{x})+\boldsymbol{A}(\boldsymbol{x}) \boldsymbol{u},
$$

where

$$
\boldsymbol{A}(\boldsymbol{x})=\left[\begin{array}{llll}
L_{g 1} L_{f}^{2} h_{1}(x) & L_{g 2} L_{f}^{2} h_{1}(x) & L_{g 3} L_{f}^{2} h_{1}(x) & L_{g 4} L_{f}^{2} h_{1}(x) \\
L_{g 1} L_{f}^{2} h_{2}(x) & L_{g 2} L_{f}^{2} h_{2}(x) & L_{g 3} L_{f}^{2} h_{2}(x) & L_{g 4} L_{f}^{2} h_{2}(x) \\
L_{g 1} L_{f}^{2} h_{3}(x) & L_{g 2} L_{f}^{2} h_{3}(x) & L_{g 3} L_{f}^{2} h_{3}(x) & L_{g 4} L_{f}^{2} h_{3}(x) \\
L_{g 1} L_{f}^{2} h_{4}(x) & L_{g 2} L_{f}^{2} h_{4}(x) & L_{g 3} L_{f}^{2} h_{4}(x) & L_{g 4} L_{f}^{2} h_{4}(x) \\
L_{g 1} L_{f}^{2} h_{5}(x) & L_{g 2} L_{f}^{2} h_{5}(x) & L_{g 3} L_{f}^{2} h_{5}(x) & L_{g 4} L_{f}^{2} h_{5}(x) \\
L_{g 1} L_{f}^{2} h_{6}(x) & L_{g 2} L_{f}^{2} h_{6}(x) & L_{g 3} L_{f}^{2} h_{6}(x) & L_{g 4} L_{f}^{2} h_{6}(x)
\end{array}\right]
$$

is the decoupling matrix. $\boldsymbol{B}(\boldsymbol{x})=L_{f}^{3} h_{i}(\boldsymbol{x}), \quad i=1, \cdots, 6$. Based on the above-mentioned linearization, the SMC method can then be used to design the controller of the vehicle height and leveling adjustment system of EAS.

\subsection{SMC Design}

Generally, the vehicle height and leveling adjustment system has high nonlinearities because of the nonlinear dynamic behaviors of the air springs and the airflow characteristics through the solenoid valve. Furthermore, the real-time variations of the payload and the system parameters also give troubles to the controller design. Thus, an effective control method is essential to solve these problems and to guarantee the vehicle height and leveling are controlled in high performance. The SMC is a representative of the robust control method and has been used in many pneumatic control systems [33-35]. The SMC design procedure contains two parts. One part is to define the sliding surfaces and the other part is to formulate an effective control law.

Consider the system model represented in equations and the major control objectives, the sliding surfaces of the vehicle height and leveling adjustment system of EAS are designed as

$$
\left\{\begin{array}{l}
s_{f r}=c_{11}\left(h_{f r}-h_{d}\right)+c_{12}\left(\dot{h}_{f r}-\dot{h}_{d}\right)+\left(\ddot{h}_{f r}-\ddot{h}_{d}\right), \\
s_{f l}=c_{21}\left(h_{f l}-h_{d}\right)+c_{22}\left(\dot{h}_{f l}-\dot{h}_{d}\right)+\left(\ddot{h}_{f l}-\ddot{h}_{d}\right), \\
s_{r l}=c_{31}\left(h_{r l}-h_{d}\right)+c_{32}\left(\dot{h}_{r l}-\dot{h}_{d}\right)+\left(\ddot{h}_{r l}-\ddot{h}_{d}\right), \\
s_{r r}=c_{41}\left(h_{r r}-h_{d}\right)+c_{42}\left(\dot{h}_{r r}-\dot{h}_{d}\right)+\left(\ddot{h}_{r r}-\ddot{h}_{d}\right), \\
s_{\theta}=c_{51}\left(\theta-\theta_{d}\right)+c_{52}\left(\dot{\theta}-\dot{\theta}_{d}\right)+\left(\ddot{\theta}-\ddot{\theta}_{d}\right), \\
s_{\varphi}=c_{61}\left(\varphi-\varphi_{d}\right)+c_{62}\left(\dot{\varphi}-\dot{\varphi}_{d}\right)+\left(\ddot{\varphi}-\ddot{\varphi}_{d}\right),
\end{array}\right.
$$

where $h_{d}$ denotes the desired vehicle height, $\theta_{d}$ and $\phi_{d}$ refer to the desired roll and pitch angles of the vehicle body. $c_{i j}(i=1, \ldots, 6, j=1,2)$ are positive constants.

The control outputs of the SMC consist of two parts. The first part is the equivalent control section and the second part is the switching control section. By differentiating the sliding surfaces $s$ for getting the equivalent control outputs of SMC, and the exponential approach law is used in the switching control section, then several new equations can be obtained as

$$
\left\{\begin{aligned}
\dot{s}_{f r} & =c_{11} \dot{e}_{f r 1}+c_{12} \dot{e}_{f r 2}+\dot{e}_{f r 3} \\
& =c_{11} e_{f r 2}+c_{12} e_{f r 3}+v_{1}=-\varepsilon_{1} \operatorname{sgn} s_{f r}-k_{1} s_{f r}, \\
\dot{s}_{f l} & =c_{21} \dot{e}_{f l 1}+c_{22} \dot{e}_{f l 2}+\dot{e}_{f l 3} \\
& =c_{21} e_{f l 2}+c_{22} e_{f l 3}+v_{2}=-\varepsilon_{2} \operatorname{sgn} s_{f l}-k_{2} s_{f l}, \\
\dot{s}_{r l} & =c_{31} \dot{e}_{r l 1}+c_{32} \dot{e}_{r l 2}+\dot{e}_{r l 3} \\
& =c_{31} e_{r l 2}+c_{32} e_{r l 3}+v_{3}=-\varepsilon_{3} \operatorname{sgn} s_{r l}-k_{3} s_{r l}, \\
\dot{s}_{r r} & =c_{41} \dot{e}_{r r 1}+c_{42} \dot{e}_{r r 2}+\dot{e}_{r r 3} \\
& =c_{41} e_{r r 2}+c_{42} e_{r r 3}+v_{4}=-\varepsilon_{4} \operatorname{sgn} s_{r r}-k_{4} s_{r r}, \\
\dot{s}_{\theta} & =c_{51} \dot{e}_{\theta 1}+c_{52} \dot{e}_{\theta 2}+\dot{e}_{\theta 3} \\
& =c_{51} e_{\theta 2}+c_{52} e_{\theta 3}+v_{5}=-\varepsilon_{5} \operatorname{sgn} s_{\theta}-k_{5} s_{\theta}, \\
\dot{s}_{\varphi} & =c_{61} \dot{e}_{\varphi 1}+c_{62} \dot{e}_{\varphi 2}+\dot{e}_{\varphi 3} \\
& =c_{61} e_{\varphi 2}+c_{62} e_{\varphi 3}+v_{6}=-\varepsilon_{6} \operatorname{sgn} s_{\varphi}-k_{6} s_{\varphi},
\end{aligned}\right.
$$

where

$$
\begin{aligned}
& \left\{\begin{array} { l } 
{ e _ { f r 1 } = h _ { f r } - h _ { d } , } \\
{ e _ { f r 2 } = \dot { h } _ { f r } - \dot { h } _ { d } , } \\
{ e _ { f r 3 } = \ddot { h } _ { f r } - \ddot { h } _ { d } , }
\end{array} \quad \left\{\begin{array} { l } 
{ e _ { f l 1 } = h _ { f l } - h _ { d } , } \\
{ e _ { f l 2 } = \dot { h } _ { f l } - \dot { h } _ { d } , } \\
{ e _ { f l 3 } = \ddot { h } _ { f l } - \ddot { h } _ { d } , }
\end{array} \quad \left\{\begin{array}{l}
e_{r l 1}=h_{r l}-h_{d}, \\
e_{r l 2}=\dot{h}_{r l}-\dot{h}_{d}, \\
e_{r l 3}=\ddot{h}_{r l}-\ddot{h}_{d},
\end{array}\right.\right.\right. \\
& \left\{\begin{array} { l } 
{ e _ { r r 1 } = h _ { r r } - h _ { d } , } \\
{ e _ { r r 2 } = \dot { h } _ { r r } - \dot { h } _ { d } , } \\
{ e _ { r r 3 } = \ddot { h } _ { r r } - \ddot { h } _ { d } , }
\end{array} \quad \left\{\begin{array} { l } 
{ e _ { \theta 1 } = \theta - \theta _ { d } , } \\
{ e _ { \theta 2 } = \dot { \theta } - \dot { \theta } _ { d } , } \\
{ e _ { \theta 3 } = \ddot { \theta } - \ddot { \theta } _ { d } , }
\end{array} \quad \left\{\begin{array}{l}
e_{\varphi 1}=\varphi-\varphi_{d}, \\
e_{\varphi 2}=\dot{\varphi}-\dot{\varphi}_{d}, \\
e_{\varphi 3}=\ddot{\varphi}-\ddot{\varphi}_{d},
\end{array}\right.\right.\right.
\end{aligned}
$$

$k_{i}(i=1, \ldots, 6)$ are the SMC parameters, $\varepsilon_{i}(i=1, \ldots, 6)$ are the gain coefficients of the switching control.

Based on Eq. (18), the control outputs of the SMC can be further described by 


$$
\boldsymbol{v}=\left[\begin{array}{c}
v_{1} \\
v_{2} \\
v_{3} \\
v_{4} \\
v_{5} \\
v_{6}
\end{array}\right]=\left[\begin{array}{c}
-\varepsilon_{1} \operatorname{sgn} s_{f r}-k_{1} s_{f r}-c_{11} e_{f r 2}-c_{12} e_{f r 3} \\
-\varepsilon_{2} \operatorname{sgn} s_{f l}-k_{2} s_{f l}-c_{21} e_{f l 2}-c_{22} e_{f l 3} \\
-\varepsilon_{3} \operatorname{sgn} s_{r l}-k_{3} s_{r l}-c_{31} e_{r l 2}-c_{32} e_{r l 3} \\
-\varepsilon_{4} \operatorname{sgn} s_{r r}-k_{4} s_{r r}-c_{41} e_{r r 2}-c_{42} e_{r r 3} \\
-\varepsilon_{5} \operatorname{sgn} s_{\theta}-k_{5} s_{\theta}-c_{51} e_{\theta 2}-c_{52} e_{\theta 3} \\
-\varepsilon_{6} \operatorname{sgn} s_{\varphi}-k_{6} s_{\varphi}-c_{61} e_{\varphi 2}-c_{62} e_{\varphi 3}
\end{array}\right]
$$

Substituting Eq. (19) into Eq. (16), the control outputs of the SMC in the original coordinates can be further obtained as [36-38]

$$
\left.\begin{array}{l}
\boldsymbol{u}= \\
\boldsymbol{A}^{-1}(\boldsymbol{x})\left(\boldsymbol{B}(\boldsymbol{x})+\left[\begin{array}{c}
-\varepsilon_{1} \operatorname{sgn} s_{f r}-k_{1} s_{f r}-c_{11} e_{f r 2}-c_{12} e_{f r 3} \\
-\varepsilon_{2} \operatorname{sgn} s_{f l}-k_{2} s_{f l}-c_{21} e_{f l 2}-c_{22} e_{f l} \\
-\varepsilon_{3} \operatorname{sgn} s_{r l}-k_{3} s_{r l}-c_{31} e_{r l 2}-c_{32} e_{r l 3} \\
-\varepsilon_{4} \operatorname{sgn} s_{r r}-k_{4} s_{r r}-c_{41} e_{r r 2}-c_{42} e_{r r 3} \\
-\varepsilon_{5} \operatorname{sgn} s_{\theta}-k_{5} s_{\theta}-c_{51} e_{\theta 2}-c_{52} e_{\theta 3} \\
-\varepsilon_{6} \operatorname{sgn} s_{\varphi}-k_{6} s_{\varphi}-c_{61} e_{\varphi 2}-c_{62} e_{\varphi 3}
\end{array}\right]\right)
\end{array}\right)
$$

\subsection{FSMC Design}

In this section, the merits of SMC and FLC are combined to address the chattering problem of SMC. This scheme can help to ensure the system stability. The FSMC is defined as a single-input-single-output system whose input is the sliding surface and output is the gain coefficient of the switching control. The sliding surfaces are fuzzified based on the universe of discourse of $s$ and the fuzzy rules are defined by triangular form and trapezoidal form of membership functions. The membership function of the output, i.e., the gain coefficient of the switching control, is defined as a singleton function, whose fuzzy sets are defined on the normalized universe of discourse \pm 1 , as shown in Figure 3. The fuzzy variables defined to describe the output membership functions are $\{\mathrm{NB}, \mathrm{N}, \mathrm{M}, \mathrm{P}, \mathrm{PB}\}$.

The basic fuzzy rule for the FSMC is defined as

$$
R^{i}: \text { if } s_{i} \text { is } Q_{s_{i}}^{n} \text { then } \varepsilon_{i} \text { is } Q_{\varepsilon_{i}}^{n}
$$

where $Q_{s_{i}}^{n}$ and $Q_{\varepsilon_{i}}^{n}$ are the input and output fuzzy sets. The fuzzy rules partition the phase plane into two semiplanes by a sliding surface. The fuzzy control rules of inference, which decide the impact of the precedent part on the retrocedent part, are defined as [39]

$\mu_{s_{i} \circ R^{i}}\left(\varepsilon_{i}\right)=\sup _{x \in s_{i}}\left[\min \left[\mu_{F_{x}^{i}}\left(s_{i}\right), \min \left[\mu_{F_{x}^{i}}\left(s_{i}\right), \mu_{\varepsilon_{i}}\left(\varepsilon_{i}\right)\right]\right]\right]$,

where $\sup _{x \in s_{i}}$ is proposed for maximum operation. The crisp output values are extracted from fuzzy outputs by using center of area defuzzification principle given as

$$
u_{f z}\left(s_{i}, \varepsilon_{i}\right)=\frac{\sum_{i} u_{f z} \mu\left(s_{i}, \varepsilon_{i}, u_{f z}\right)}{\sum_{i} \mu\left(s_{i}, \varepsilon_{i}, u_{f z}\right)} .
$$

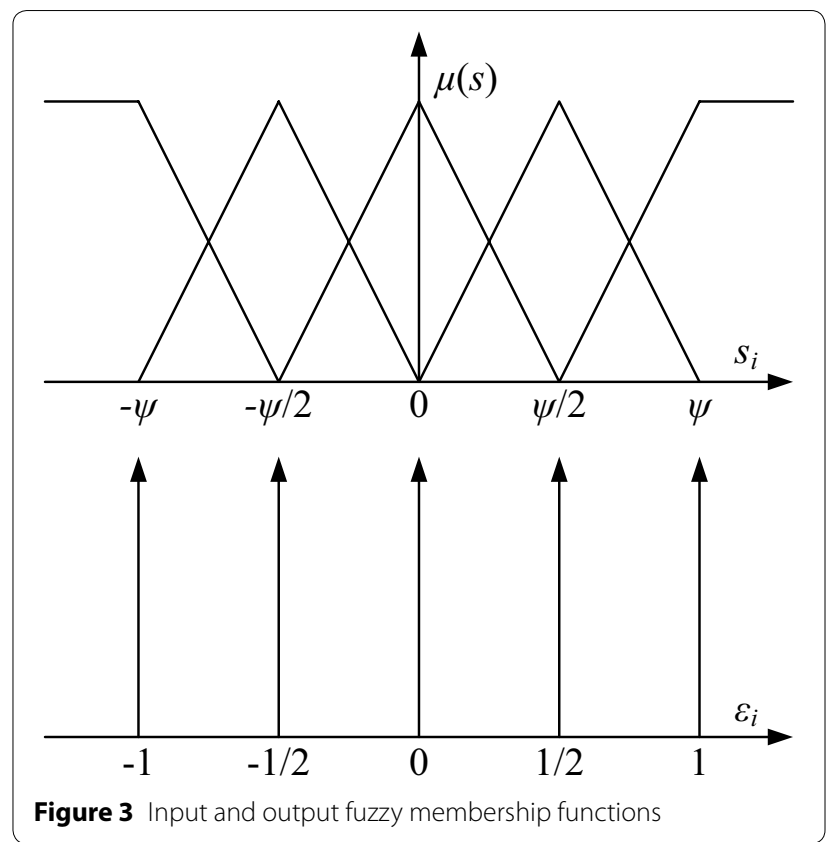

Then, the outputs of the FSMC can be obtained. The FSMC determines a mapping from the sliding surface to the system outputs. The control rules of the FSMC are contrary to the modified SMC on the separated semiplane, where the magnitudes of the fuzzy control signals are proportional to the states away from the sliding surface $s=0$. Therefore, the FSMC actions will help to ensure the system state vectors stay on the sliding surfaces, so as to realize the system optimal control performance.

The general control structure of the proposed FSMC is shown in Figure 4. The gain coefficients of the SMC are determined vigorously by the FLC according to the sliding surfaces, which are defined based on the errors between the actual system performance indices and the desired system performance indices. Meanwhile, the vehicle heights at each corner are passed through a lowpass filter of $2 \mathrm{~Hz}$ to filter out the road roughness disturbances. Since the vehicle height and leveling adjustment system of EAS uses the on-off solenoid valves to regulate the air masses inside the air springs, the on-off statuses of the six solenoid valves are further controlled by employing the pulse width modulation (PWM) technology in this paper. The duty ratios of the on-off status of the solenoid valve are then given as

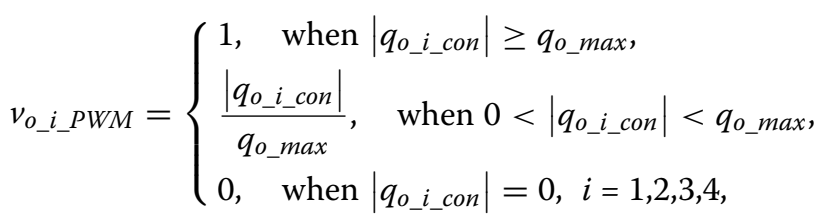




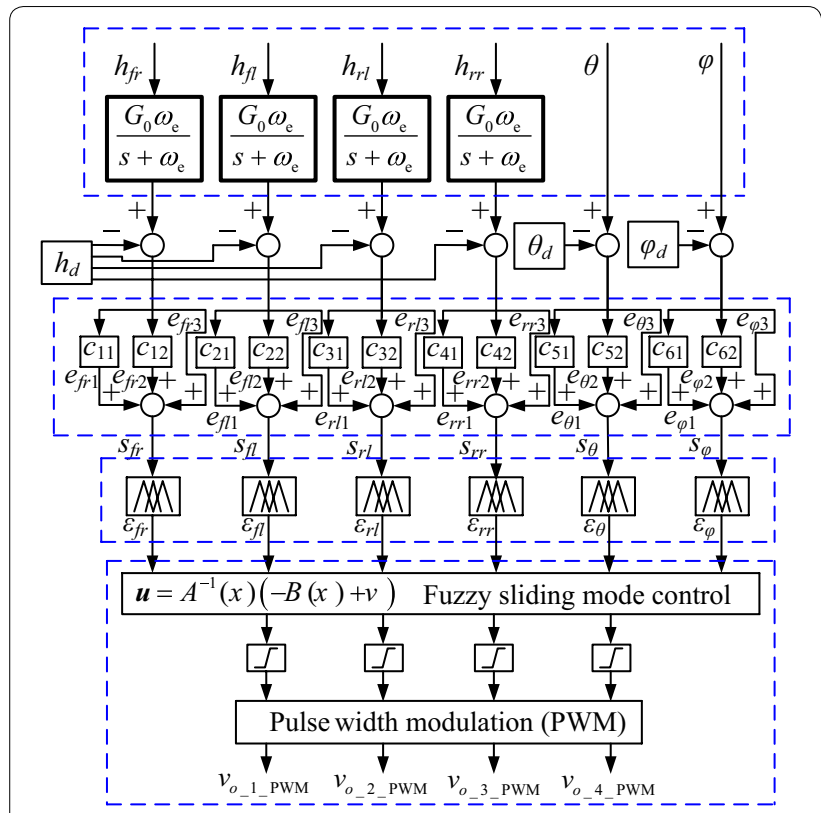

Figure 4 General control structure of the FSMC

\section{Table 1 System parameters}

\begin{tabular}{ll}
\hline Parameter & Value \\
\hline Mass of the vehicle body $m_{s}(\mathrm{~kg})$ & 11560 \\
Roll moment of inertia $I_{\theta}\left(\mathrm{kg} \cdot \mathrm{m}^{2}\right)$ & 16750 \\
Pitch moment of inertia $I_{\varphi}\left(\mathrm{kg} \cdot \mathrm{m}^{2}\right)$ & 85036 \\
Unsprung mass of front wheel $m_{f r} m_{f l}(\mathrm{~kg})$ & 435 \\
Unsprung mass of rear wheel $m_{r \prime} m_{r r}(\mathrm{~kg})$ & 845 \\
Distance from the centre of gravity to front axis $I_{f}(\mathrm{~m})$ & 3.32 \\
Distance from the centre of gravity to front axis $I_{r}(\mathrm{~m})$ & 2.38 \\
Half of the wheel-track $I_{a}(\mathrm{~m})$ & 1.21 \\
Front wheel damping coefficients $C_{d 1}, C_{d 2}\left(\mathrm{~N} \cdot \mathrm{s} \cdot \mathrm{m}^{-1}\right)$ & 11085 \\
Rear wheel damping coefficients $C_{d d^{\prime}}, c_{d 4}\left(\mathrm{~N} \cdot \mathrm{s} \cdot \mathrm{m}^{-1}\right)$ & 13900 \\
Tyre stiffness $k_{t f} k_{t r}(\mathrm{kN} / \mathrm{m})$ & 650 \\
Cross-sectional area of the air spring $A_{a s i}\left(\mathrm{~m}^{2}\right)$ & 0.042 \\
Cross-sectional area of the solenoid valve $s\left(\mathrm{~m}^{2}\right)$ & $7 \times 10^{-6}$ \\
Volume of the pipeline $V_{p i}\left(\mathrm{~m}^{3}\right)$ & $1.7 \times 10^{-4}$ \\
Air pressure of the air reservoir $P_{h}(\mathrm{MPa})$ & 1.8 \\
Air pressure of the environment $P_{e}(\mathrm{~Pa})$ & $1.01 \times 10^{5}$ \\
Air temperature $T(\mathrm{~K})$ & 293.15 \\
Universal gas constant $R\left(\mathrm{~J} \cdot \mathrm{kg}{ }^{-1} \cdot \mathrm{K}^{-1}\right)$ & 287.1 \\
Polytropic index $k$ & 1.4 \\
Critical pressure ratio $b$ & 0.528 \\
\hline
\end{tabular}

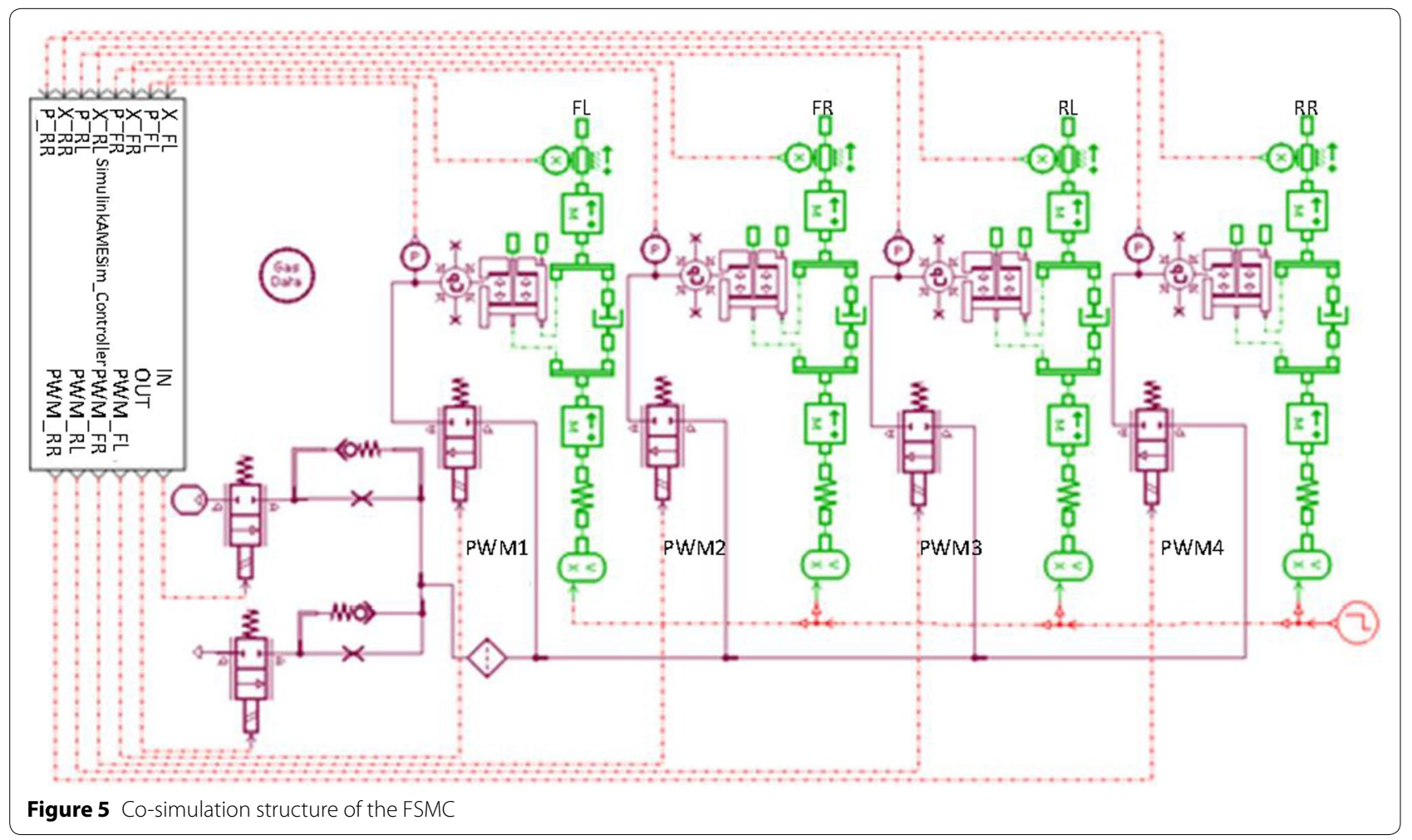


where $q_{\text {o_icon }}$ refer to the air mass flow rates through the air spring solenoid valves, which are controlled by the proposed FSMC. $q_{o \text { max }}$ refers to the maximum air mass flow rate through the air spring solenoid valve when the solenoid valve is fully opened.

The meaning of Eq. (23) is given as follows:

(1) When the absolute values of the desired air mass flow rates through the air spring solenoid valves are larger than the maximum air mass flow rates, the duty ratios of the on-off solenoid valves are defined as 1.

(2) When the absolute values of the desired air mass flow rates through the air spring solenoid valves are less than the maximum air mass flow rates, the duty ratios of the on-off solenoid valves are defined as the desired air mass flow rates divided by the maximum air mass flow rates.

(3) When the desired air mass flow rates through the air spring solenoid valves are zero, the solenoid valves should be closed.
On this basis, the on-off statuses of the charging solenoid valve and the discharging solenoid valve also have the following logical relationships with the on-off statuses of the four air spring solenoid valves

$\left\{\begin{array}{l}{\left[\delta_{c}=1 \mid \delta_{\mathrm{d}}=1\right] \leftrightarrow\left[\delta_{a}^{f r}=1\left|\delta_{a}^{f l}=1\right| \delta_{a}^{r l}=1 \mid \delta_{a}^{r r}=1\right],} \\ \delta_{c}+\delta_{\mathrm{d}} \leq 1\end{array}\right.$

where $\delta_{c}$ and $\delta_{d}$ are the on-off statuses of the charging solenoid valve and the discharging solenoid valve respectively, $\delta_{a}^{f r}, \delta_{a}^{f l}, \delta_{a}^{r l}$ and $\delta_{a}^{r r}$ refer to the on-off statuses of the four air spring solenoid valves.

\section{Simulation Study}

To verify the control performance of the proposed FSMC method, the simulation study of the controller is conducted. The simulation program is composed of the system mechanism model and the FSMC controller. Among them, the nonlinear model of the vehicle height and leveling adjustment system of EAS is developed on the basis
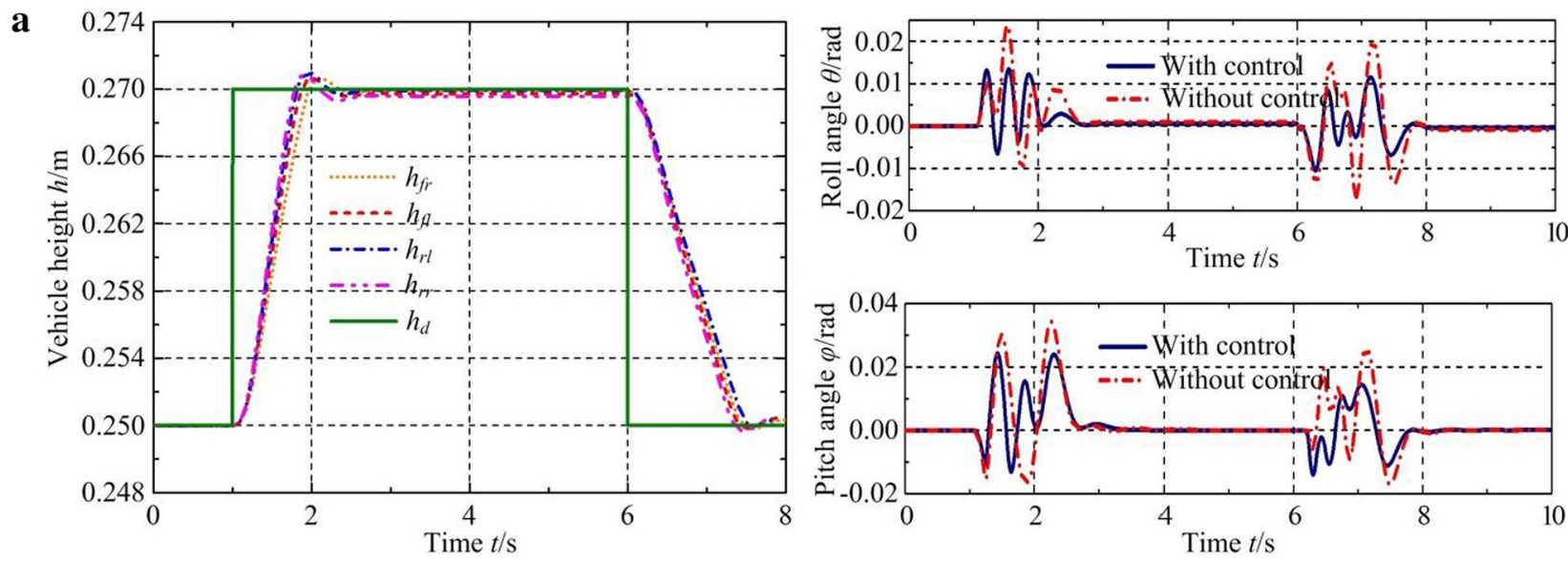

$\mathbf{b}$

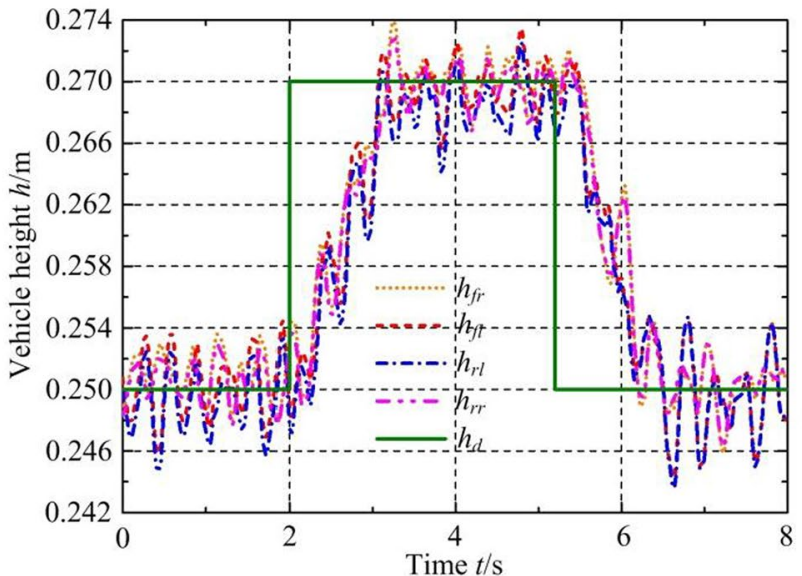

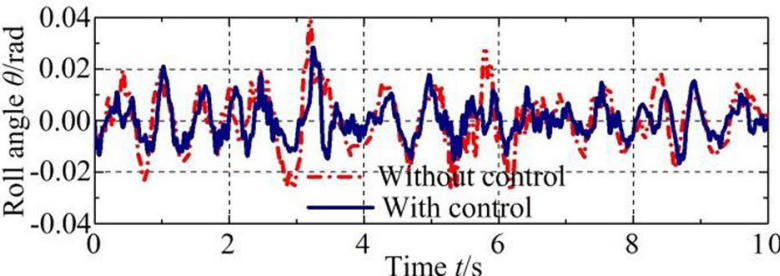

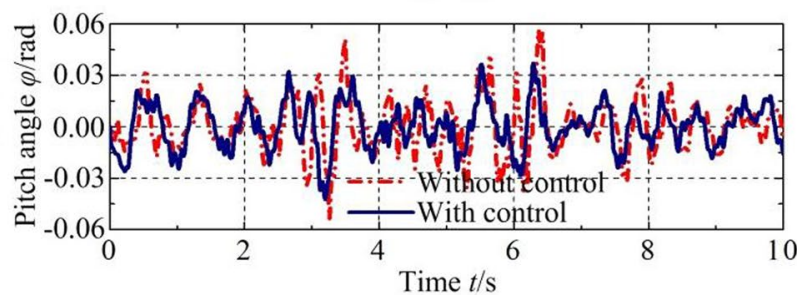

Figure 6 Co-simulation results. a Simulation results of the vehicle height and posture adjustment maneuver during standstill. b Simulation results of the vehicle height and posture adjustment maneuver during driving. 
Table 2 Analysis of the co-simulation results

\begin{tabular}{|c|c|c|c|c|c|c|c|c|}
\hline \multirow{2}{*}{\multicolumn{3}{|c|}{ Control performance }} & \multicolumn{6}{|c|}{ Simulation scenarios } \\
\hline & & & \multicolumn{3}{|c|}{ During standstill } & \multicolumn{3}{|l|}{ During driving } \\
\hline \multicolumn{3}{|l|}{ Vehicle height } & Desired value & Actual value & Precision (\%) & Desired value & Actual value & Precision (\%) \\
\hline \multirow[t]{4}{*}{ Height lifting } & \multicolumn{2}{|c|}{$h_{f r}(\mathrm{~m})$} & 0.270 & 0.2698 & 99.92 & 0.270 & 0.2693 & 99.74 \\
\hline & \multicolumn{2}{|c|}{$h_{f l}(\mathrm{~m})$} & 0.270 & 0.2697 & 99.89 & 0.270 & 0.2691 & 99.67 \\
\hline & \multicolumn{2}{|c|}{$h_{r l}(\mathrm{~m})$} & 0.270 & 0.2696 & 99.85 & 0.270 & 0.2685 & 99.44 \\
\hline & \multicolumn{2}{|c|}{$h_{r r}(\mathrm{~m})$} & 0.270 & 0.2696 & 99.85 & 0.270 & 0.2690 & 99.63 \\
\hline \multirow[t]{4}{*}{ Height lowering } & \multicolumn{2}{|c|}{$h_{f r}(\mathrm{~m})$} & 0.250 & 0.2502 & 99.92 & 0.250 & 0.2493 & 99.72 \\
\hline & \multicolumn{2}{|c|}{$h_{f l}(\mathrm{~m})$} & 0.250 & 0.2503 & 99.88 & 0.250 & 0.2505 & 99.80 \\
\hline & \multicolumn{2}{|c|}{$h_{r l}(\mathrm{~m})$} & 0.250 & 0.2502 & 99.92 & 0.250 & 0.2491 & 99.64 \\
\hline & \multicolumn{2}{|c|}{$h_{r r}(\mathrm{~m})$} & 0.250 & 0.2503 & 99.88 & 0.250 & 0.2506 & 99.76 \\
\hline Posture & \multicolumn{3}{|c|}{ Without control } & With control & Decrease (\%) & Without control & With control & Decrease (\%) \\
\hline \multirow[t]{2}{*}{ Height lifting } & $\theta(\mathrm{rad})$ & \multicolumn{2}{|c|}{0.022} & 0.013 & 40.91 & 0.040 & 0.029 & 27.50 \\
\hline & $\varphi(\mathrm{rad})$ & \multicolumn{2}{|c|}{0.035} & 0.022 & 37.14 & 0.053 & 0.042 & 20.75 \\
\hline \multirow[t]{2}{*}{ Height lowering } & $\theta(\mathrm{rad})$ & \multicolumn{2}{|c|}{0.019} & 0.011 & 42.11 & 0.028 & 0.017 & 39.29 \\
\hline & $\varphi(\mathrm{rad})$ & \multicolumn{2}{|c|}{0.023} & 0.016 & 30.43 & 0.054 & 0.036 & 33.33 \\
\hline
\end{tabular}

of the dynamic analysis of the pneumatic system and programmed by AMESim, which can reflect the actual dynamic characteristics of the system more accurately [40]. Then, the co-simulation study of the FSMC performance is conducted based on Matlab and AMESim. The co-simulation structure of the FSMC is illustrated in Figure 5.

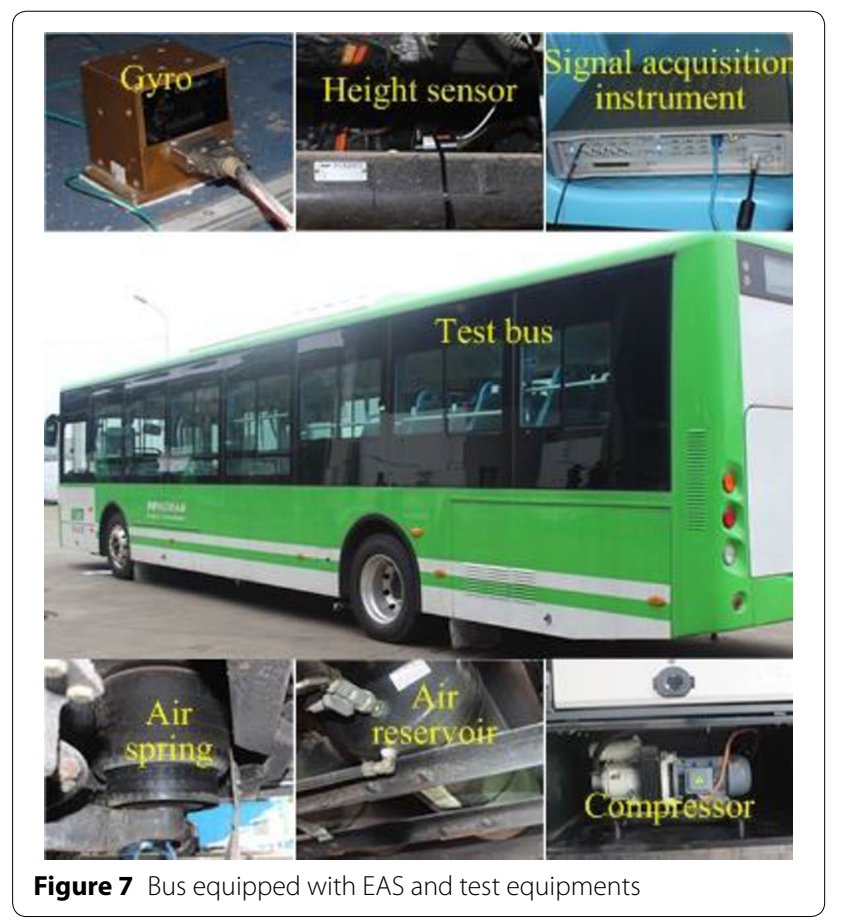

The parameters of the target full-car EAS system and the city bus, considered in the simulation calculations, are shown in Table 1.

The control objectives of the proposed method are to ensure the vehicle height can be controlled in high precision and the peak values of the roll and pitch angles of the vehicle body can be reduced significantly despite payload variations and parameters difference. To obtain the simulation calculation results, the road roughness input is given mathematically as $[41,42]$

$$
\dot{z}_{0}(t)=-0.111\left[u z_{0}(t)+40 \sqrt{G_{q}\left(n_{0}\right) u} w(t)\right],
$$

where $u$ denotes the vehicle speed, $G_{q}\left(n_{0}\right)$ refers to the road random roughness coefficient and $w(t)$ refers to the Gaussian white noise. The road roughness used in simulation and vehicle tests corresponds to the road of class $B$ $\left(G_{q}\left(n_{0}\right)=64 \times 10^{-6} \mathrm{~m}^{3}\right)[43,44]$.

The initial vehicle heights at four corners of the vehicle body are defined as $0.25 \mathrm{~m}$. The simulation results of the FSMC method applied to the full-car EAS system are shown in Figure 6.

To better show the dynamic performance of the FSMC strategy, the actual vehicle heights at four corners and the peak values of the roll and pitch angles of the vehicle body are illustrated in Table 2. Note that the values of vehicle height are the mean values under steady state.

As shown in Figure 6 and Table 2, the controller shows high precision in the vehicle height adjustment, and the peak values of the roll and pitch angles of the vehicle 
body are also reduced significantly. These results show the effectiveness of the proposed controller.

\section{Vehicle Tests}

In this section, actual vehicle tests for verifying the FSMC performance are reported. As shown in Figure 7, the actual vehicle tests are performed with a city bus equipped with a full-car vehicle height control system. The on-off solenoid valves used to control the air mass
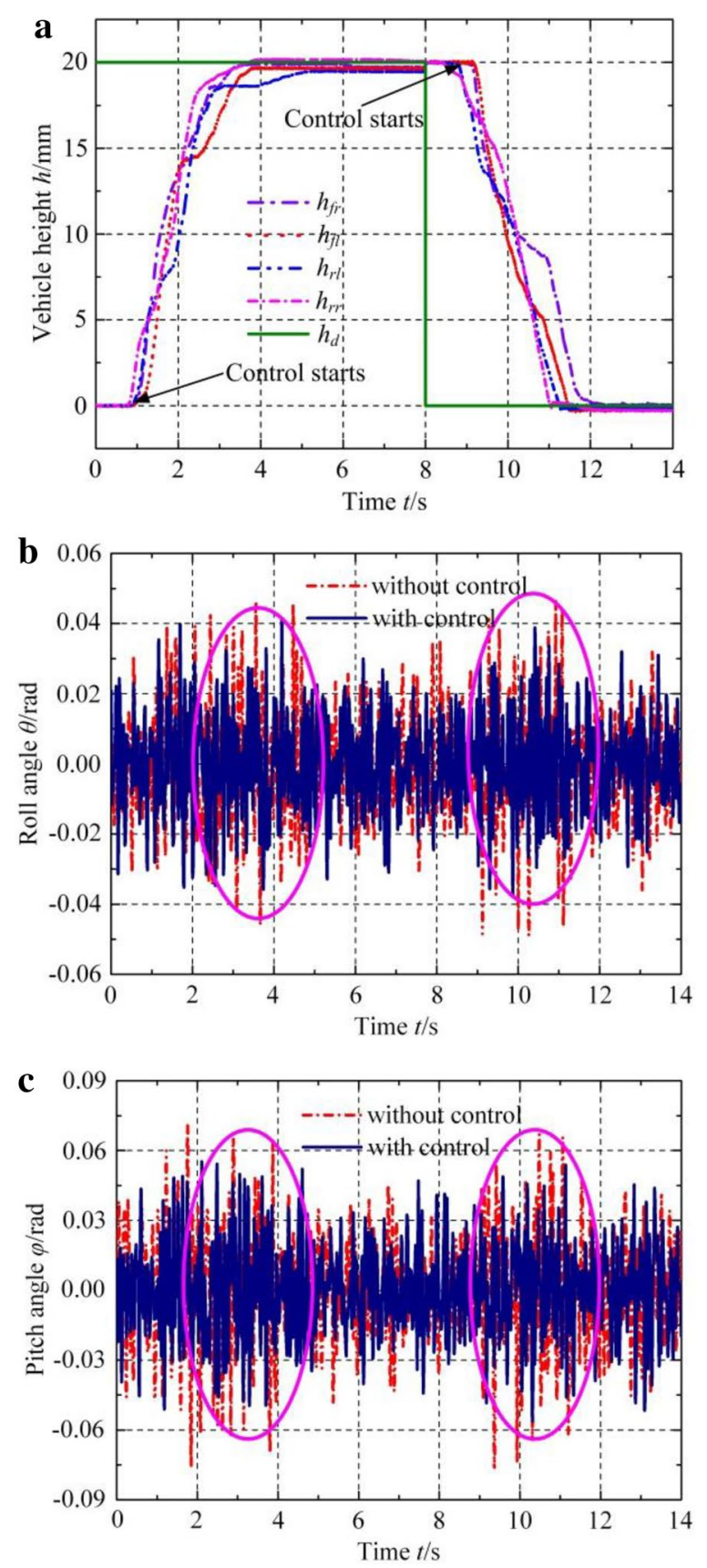

Figure 8 Actual vehicle test results flow rates are integrated together. The air reservoir and the compressor are equipped to provide high-pressure air. In terms of sensors, the roll and pitch angles of the vehicle body are measured by the gyro, and the vehicle height is measured by displacement-type height sensor.

The system controller designed based on FSMC is implemented using a D2P (development to production) rapid control prototyping platform, which can generate the control code directly based on the compilation of project files established in Simulink. The initial static vehicle height is assumed to be zero in the vehicle test.

Figure 8 shows the actual vehicle test results for the height adjustment procedures. As shown in Figure 8(a), the proposed FSMC controller can regulate the vehicle heights at four corners to the desired values with high precision. In addition, according to the test results shown in Figure 8(b) and (c), the proposed FSMC controller can also maintain the posture stability. It can also be found that the peak values of the roll and pitch angles have significant decrease amplitudes under the control of our FSMC controller. Note that the control strategy designed in this paper is to adjust the vehicle height and the roll and pitch angles of the vehicle body, this may cause the increase of the vertical acceleration of the vehicle body. During the vehicle tests, the vertical accelerations of the vehicle body before and after control are also compared, and the comparison results show that the vertical acceleration of the vehicle body doesn't have a significant increase, thus the vehicle ride comfort is guaranteed in this study.

\section{Conclusions}

(1) A FSMC controller with adaptive ability has been developed in this paper for solving the vehicle height and leveling control problem of an EAS system. Based on the analysis of the system working principle, a nonlinear mechanism model is established to describe the dynamic behaviors of the system and to derive the control law.

(2) As a robust control method, the FSMC technique can be used to ensure the vehicle height adjustment precision and stabilize the posture of the vehicle body during the vehicle height adjustment procedure of EAS system, i.e., the peak values of the roll and pitch angles can be decreased significantly.

(3) The resulting FSMC control algorithm can be implemented by the D2P rapid control prototyping platform, and on this basis, the actual vehicle tests of the control performance is conducted. The simulation and test results illustrate that the proposed FSMC method can control the vehicle height with high precision and regulate the roll and pitch angles of the vehicle body effectively. The proposed approach can be used to improve the performance of EAS system. 


\section{Authors' contributions}

LC was in charge of the whole trial; X-QS wrote the manuscript; Y-FC, C-CY and S-HW assisted with sampling and laboratory analyses. All authors read and approved the final manuscript.

\section{Author details}

${ }^{1}$ Automotive Engineering Research Institute, Jiangsu University, Zhenjiang 212013, China. ${ }^{2}$ School of Automotive and Traffic Engineering, Jiangsu University, Zhenjiang 212013, China.

\section{Authors' Information}

Xiao-Qiang Sun, born in 1989, is currently a lecturer at Automotive Engineering Research Institute, Jiangsu University, China. He received his PhD degree from Jiangsu University, China, in 2016. His research interests include electronically controlled air suspension and engineering application of advanced control theory. E-mail: sunxqujs@126.com

Ying-Feng Cai, born in 1985, is currently an associate professor and a master candidate supervisor at Automotive Engineering Research Institute, Jiangsu University, China. She received her PhD degree from Southeast University, China, in 2013. Her main research interests include vehicle system dynamics and intelligent automobile. E-mail: caicaixiao0304@126.com

Chao-Chun Yuan, born in 1978, is currently an associate professor and a master candidate supervisor at Automotive Engineering Research Institute, Jiangsu University, China. He received his PhD degree from Jiangsu University, China, in 2007. His main research interests include vehicle system dynamics and intelligent automobile. E-mail: yuancc_78@163.com

Shao-Hua Wang, born in 1978, is currently an associate professor and a master candidate supervisor at School of Automotive and Traffic Engineering, Jiangsu University, China. His main research interests include electronically controlled air suspension and hybrid electric vehicle. E-mail:wsh@ujs.edu.cn

Long Chen, born in 1958, is currently a professor and a PHD candidate supervisor at Automotive Engineering Research Institute, Jiangsu University, China. His main research interests include modeling and control of vehicle dynamic systems. E-mail: chenlong@ujs.edu.cn

\section{Competing interests}

The authors declare no competing financial interests.

\section{Ethics approval and consent to participate}

Not applicable.

\section{Funding}

Supported by National Natural Science Foundation of China (Grant Nos. 51375212, 61601203), Priority Academic Program Development (PAPD) of Jiangsu Higher Education Institutions of China, Key Research and Development Program of Jiangsu Province (BE2016149), and Jiangsu Provincial Natural Science Foundation of China (BK20140555).

\section{Publisher's Note}

Springer Nature remains neutral with regard to jurisdictional claims in published maps and institutional affiliations.

Received: 13 November 2016 Accepted: 16 March 2018 Published online: 10 April 2018

\section{References}

[1] Xiao-Qiang Sun, Ying-Feng Cai, Shao-Hua Wang, et al. A hybrid approach to modeling and control of vehicle height for electronically controlled air suspension. Chinese Journal of Mechanical Engineering, 2016, 29(1): 152-162.

[2] Zhi-Hong Yin, A Khajepour, Dong-Pu Cao, et al. A new pneumatic suspension system with independent stiffness and ride height tuning capabilities. Vehicle System Dynamics, 2012, 50(12): 1735-1746.

[3] W K Anakwa, D R Thomas, S C Jones, et al. Development and control of a prototype pneumatic active suspension system. IEEE Transactions on Education, 2002, 45(1): 43-49.
[4] Ming-Ming Dong, Zhen-Xing Luo. Statistical linearization on 2 DOFs hydropneumatic suspension with asymmetric non-linear stiffness. Chinese Journal of Mechanical Engineering, 2015, 28(3): 504-510.

[5] Jin Gao, Xiu-Jian Yang, Zi-Ru Niu, et al. Performance of suspension and full vehicle embedded in structure-based bushing. Journal of Jiangsu University: Natural Science Editions, 2015, 36(4): 398-405. (in Chinese)

[6] Zhi-Cheng Wu, Cong Chen. Handling stability of three-axle vehicle with dual-front-axle-steering system. Journal of Jiangsu University: Natural Science Editions, 2016, 37(6): 640-644. (in Chinese)

[7] A Nieto, A Morales, J Trapero, et al. An adaptive pneumatic suspension based on the estimation of the excitation frequency. Journal of Sound and Vibration, 2011, 330(9): 1891-1903.

[8] I Maciejewski. Control system design of active seat suspensions. Journal of Sound and Vibration, 2012, 331(6): 1291-1309.

[9] C Lee, V Goverdovskiy. A multi-stage high-speed railroad vibration isolation system with "negative" stiffness. Journal of Sound and Vibration, 2012, 331(4): 914-921.

[10] I Maciejewski, T Krzyzynski, L Meyer. Control system synthesis of seat suspensions used for protection of working machine operators. Vehicle System Dynamics, 2014, 52(11): 1355-1371.

[11] Xiao-Qiang Sun, Ying-Feng Cai, Long Chen, et al. Vehicle height and posture control of the electronic air suspension system using the hybrid system approach. Vehicle System Dynamics, 2016, 54(3): 328-352.

[12] Jun Zhang, Shuai Lei, Si-Sheng Duan. Simulation and experimental research on air suspension couch height control. Journal of Wuhan University of Technology, 2012, 34(4): 123-126. (in Chinese)

[13] H Kim, H Lee. Height and leveling control of automotive air suspension system using sliding mode approach. IEEE Transactions on Vehicular Technology, 2011, 60(5): 2027-2041.

[14] Xing Xu, Kong-Kang Zhou, Nan-Nan Zou, et al. Hierarchical control of ride height system for electronically controlled air suspension based on variable structure and fuzzy control theory. Chinese Journal of Mechanical Engineering, 2015, 28(5): 945-953.

[15] Jiong-Kang Lin, Ka-Wai Cheng, Zhu-Zhang, et al. Adaptive sliding mode technique-based electromagnetic suspension system with linear switched reluctance actuator. IET Electric Power Applications, 2015, 9(1): 50-59.

[16] E Ozkop, I H Altas, H I Okumus, et al. A fuzzy logic sliding mode controlled electronic differential for a direct wheel drive EV. International Journal of Electronics, 2015, 102(11): 1919-1942.

[17] Y Toshio. Design of an adaptive fuzzy sliding mode control for uncertain discrete-time nonlinear systems based on noisy measurements. International Journal of Systems Science, 2016, 47(3): 617-630.

[18] Hai-Long Zhang, En-Rong Wang, Ning Zhang, et al. Semi-active sliding mode control of vehicle suspension with magneto-rheological damper. Chinese Journal of Mechanical Engineering, 2015, 28(1): 63-75.

[19] Ting-Ting Duan, Chun-Yan Wang, Wan-Zhong Zhao, et al. Sliding modePID control of driving system for motorized wheels vehicle. Journal of Jiangsu University: Natural Science Editions, 2015, 36(3): 260-264. (in (hinese)

[20] Li-Ying Hao, J H Park, Dan Ye. Fuzzy logic systems-based integral sliding mode fault-tolerant control for a class of uncertain non-linear systems. IET Control Theory and Applications, 2016, 10(3): 300-311.

[21] Jun-Tao Fei, Ming-Yuan Xin. Adaptive fuzzy backstepping sliding mode control for MEMS gyroscope. Journal of Intelligent and Fuzzy Systems, 2014 27(2): 817-826.

[22] Xiao-Qiang Sun, Long Chen, Shao-Hua Wang, et al. Vehicle height control of electronic air suspension system based on mixed logical dynamica modelling. Science China Technological Sciences, 2015, 58(11): 1804-1904.

[23] Xing Xu, Long Chen, Li-Qin Sun, et al. Dynamic ride height adjusting controller of ECAS vehicle with random road disturbances. Mathematical Problems in Engineering, 2013, 439515

[24] H Sean, Q L Minh, T Mahdi, et al. Improved tracking and switching performance of an electro-pneumatic positioning system. Mechatronics, 2012 22(1): 1-12

[25] Xue-Liang Ju, P Wu, P R Weckler, et al. Newly- simplified method for hydraulic design of micro-irrigation laterals based on emission uniformity. Journal of Drainage and Irrigation Machinery Engineering, 2015, 33(8): 691-700. (in Chinese)

[26] S J Lee. Development and analysis of an air spring model. International Journal of Automotive Technology, 2010, 11(4): 471- 479. 
[27] Shi-Hao Yuan. Partial port throttle performance based on standard orthogonal polynomial fitting. Journal of Drainage and Irrigation Machinery Engineering, 2015, 33(12): 1056-1061. (in Chinese)

[28] Hong-Lin Xue, Chi Zhang, Yan-Jun Li, et al. Analysis of transient flow in vertical mixed-flow pumping system during pump stopping period by closing valve in two-phase mode. Journal of Drainage and Irrigation Machinery Engineering, 2015, 33(11): 953-959. (in Chinese)

[29] Hai-Ping Du, Nong Zhang. Fuzzy control for nonlinear uncertain electrohydraulic active suspensions with input constraint. IEEE Transactions on Fuzzy System, 2009, 17(2): 343-356.

[30] Lei Liu, Yi-Qi Zhou, Yong-Zhen Mi, et al. Performance parameter optimization of excavator cab shock absorbers based on Kriging method. Journal of Jiangsu University: Natural Science Editions, 2015, 36(5): 497-503. (in (hinese)

[31] S S Kim, R J Michael, A Abdou, et al. A fixed point approach to stability of cubic lie derivatives in banach algebras. Journal of Computational Analysis and Applications, 2015, 19(2): 378-388.

[32] D H Lim, W H Sohn. Lie derivative of shape operator on real hypersurfaces in a complex space form. Far East Journal of Mathematical Sciences, 2015, 98(7): 883-895.

[33] A Girin, F Plestan, X Brun, et al. High-order sliding-mode controllers of an electropneumatic actuator: application to an aeronautic benchmark. IEEE Transactions on Control Systems Technology, 2009, 17(3): 633-645.

[34] K Xing, J Huang, Y Wang, et al. Tracking control of pneumatic artificial muscle actuators based on sliding mode and non-linear disturbance observer. IET Control Theory and Applications, 2010, 4(10): 2058-2070.

[35] Hai-Fei Wang, Yan Kong, Fei-Ning Xu, et al. Hydraulic brake energy recovery technology of sanitation construction. Journal of Jiangsu University: Natural Science Editions, 2015, 36(6): 621-626. (in Chinese)
[36] U Vadim. Discussion aspects of high-order sliding mode control. IEEE Transactions on Automatic Control, 2016, 61(3): 829-833.

[37] M P Adria, V I Enric, C P Angel, et al. Interleaved digital power factor correction based on the sliding-mode approach. IEEE Transactions on Power Electronics, 2016, 31(6): 4641-4653.

[38] Peng-Yun Song, Ying Li, Ai-Lin Ma. An approximate analytical method of gas film pressure in non-parallel gap of spiral groove dry gas seal. Journal of Drainage and Irrigation Machinery Engineering, 2015, 33(12): 10491055. (in Chinese)

[39] G B Koo, J B Park, Y H Joo. Intelligent digital redesign for non-linear systems: observer-based sampled-data fuzzy control approach. IET Control Theory and Applications, 2016, 10(1): 1-9.

[40] Sheng-Li Wei, Hong-Kun Lu, Xian-Yin Leng, et al. Numerical simulation of impinging convexity on partition combustion system performance of diesel engines. Journal of Jiangsu University: Natural Science Editions, 2015, 36(5): 509-515. (in Chinese)

[41] Zhi-Cheng Wu, Si-Zhong Chen, Lin Yang, et al. Model of road roughness in time domain based on rational function. Transactions of Beijing Institute of Technology, 2009, 29(9): 795-798. (in Chinese)

[42] Zhong-Xing Li, Jian-Yu Huang, Ya-Wei Liu, et al. Modeling and simulation on white noise of road roughness in time domain. Journal of Jiangsu University: Natural Science Editions, 2016, 37(5): 503-506. (in Chinese)

[43] J J Rath, K C Veluvolu, M Defoort. Adaptive super-twisting observer for estimation of random road excitation profile in automotive suspension systems. Scientific World Journal, 2014, 2014: 1-8.

[44] X Q Sun, L Chen, S H Wang, et al. Performance investigation of vehicle suspension system with nonlinear ball-screw inerter. International Journal of Automotive Technology, 2016, 17(3): 399- 408.

\section{Submit your manuscript to a SpringerOpen ${ }^{\odot}$ journal and benefit from:}

- Convenient online submission

- Rigorous peer review

- Open access: articles freely available online

- High visibility within the field

Retaining the copyright to your article

Submit your next manuscript at $\boldsymbol{\nabla}$ springeropen.com 